\title{
Cell-Autonomous Mechanisms and Myelin-Associated Factors Contribute to the Development of Purkinje Axon Intracortical Plexus in the Rat Cerebellum
}

\author{
Sara Gianola, ${ }^{1}$ Tiziana Savio, ${ }^{2}$ Martin E. Schwab, ${ }^{3}$ and Ferdinando Rossi ${ }^{1}$ \\ ${ }^{1}$ Department of Neuroscience, Rita Levi Montalcini Centre for Brain Repair, University of Turin, I-10125 Turin, Italy, ${ }^{2}$ Department of Experimental \\ Medicine, University of Genoa, I-16132 Genoa, Italy, and ${ }^{3}$ Swiss Federal Institute of Technology, Brain Research Institute, University of Zurich, CH-8057 \\ Zurich, Switzerland
}

\begin{abstract}
The highly specific connection patterns of the mature CNS are shaped through finely regulated processes of axon growth and retraction. To investigate the relative contribution of cell-autonomous mechanisms and extrinsic cues in these events, we examined the development of Purkinje axon intracortical plexus in the rat cerebellum. During the first postnatal week, several new processes sprout from focal swellings along the initial portion of the Purkinje neurite and spread in the granular layer. Intense structural plasticity occurs during the following week, with pruning of collateral branches and remodeling of terminal arbors. The mature distribution of the Purkinje infraganglionic plexus, confined within the most superficial portion of the granular layer, is attained at approximately postnatal day 15 . A similar neuritic branching pattern is also developed by Purkinje cells grown in cultures of dissociated cerebellar cells or transplanted to extracerebellar CNS regions, suggesting that cell-autonomous mechanisms contribute to determining the Purkinje axon phenotype.

The structural remodeling of Purkinje intracortical plexus is concomitant with the development of cerebellar myelin. To ask whether myelin-associated factors contribute to the morphological maturation of Purkinje neurites, we prevented normal myelinogenesis by killing oligodendrocyte precursors with $5^{\prime}$-azacytidine or by applying neutralizing antibodies against the myelin-associated neurite growth inhibitor Nogo-A. In both conditions, Purkinje axons retained exuberant branches, and the terminal plexus spanned the entire extent of the granular layer. Thus, the formation of Purkinje axon collaterals is, in part, controlled by intrinsic determinants, but their growth and distribution are regulated by environmental signals, among which are myelin-derived cues.
\end{abstract}

Key words: Nogo; myelin-associated neurite growth inhibitory proteins; axonal plasticity; sprouting; pruning; neuritic branching; synaptogenesis; myelinogenesis; axon growth

\section{Introduction}

The specific wiring of neural circuits is achieved through complex mechanisms of neuritic growth and retraction, leading to development of characteristic patterns of axon branching, distributed over precise target domains. Several lines of evidence show that branch formation is elicited and directed by extrinsic cues (O'Leary et al., 1990; Acebes and Ferrus, 2000; Kalil et al., 2000; Özdinler and Erzurumlu, 2002; Soussi-Yanicostas et al., 2002). On the other hand, certain neurons develop characteristic neuritic patterns even when they grow into an unusual environment, suggesting that cell-autonomous mechanisms may be also relevant to determining the axon phenotype (Acklin and Nicholls, 1990; Canal et al., 1998; Bhide and Frost, 1999). Similarly, although intrinsic changes of maturing neurons may contribute to the progressive decline of neuritic growth potential (Davies, 1994; Fawcett, 2001), the structural remodeling that shapes ma-

Received Nov. 25, 2002; revised Feb. 21, 2003; accepted March 24, 2003

This work was supported by grants from Ministero dell'Università e della Ricerca Scientifica e Tecnologica, Ministero della Sanità Progetto Alzheimer (Grant 300RFA00/01-05), Fondazione Cavalieri Ottolenghi of Turin, and University of Turin. We are grateful to Lorenzo Magrassi for critical comments on this manuscript. We are indebted to Novartis Pharma AG for kindly providing us with the 11 C7 anti-Nogo-A antibody. We also thank Luisella Milano for technical assistance.

Correspondence should be addressed to Ferdinando Rossi, Rita Levi Montalcini Centre for Brain Repair, Department of Neuroscience, University of Turin, Corso Raffaello 30, I-10125 Turin, Italy. E-mail: ferdinando.rossi@unito.it. Copyright $\odot 2003$ Society for Neuroscience $\quad$ 0270-6474/03/234613-12\$15.00/0 ture connectivity is dependent on environmental signaling, including competitive interactions with other neurons (Goodman and Shatz, 1993; Lichtman and Colman, 2000) and growthinhibitory molecules issued by glial cells (Schwab et al., 1993; Huber and Schwab, 2000). Among the latter, myelin-associated molecules, such as Nogo-A, contribute to channel-developing axons along their pathways (Schwab and Schnell, 1991; Colello and Schwab, 1994) to restrict structural plasticity at the end of development (Kapfhammer and Schwab, 1994a,b; Schwegler et al., 1995; Vanek et al., 1998) and to regulate neuritic branching in vitro (Shen et al., 1998).

To investigate the relative contribution of intrinsic properties and environmental cues in the shaping of precise neuritic patterns, we examined the development of Purkinje axon collateral branches. Ramón y Cajal (1911) reported that initially exuberant Purkinje intracortical plexus undergoes structural remodeling, leading to confinement of terminal branches within precise cortical domains (supraganglionic and infraganglionic plexus). This issue has been scantily investigated thereafter, and the mechanisms that regulate the growth and plasticity of Purkinje axon collaterals remain mostly unclear. The morphological maturation of intracortical plexus is disrupted after $\mathrm{x}$-irradiation (Crepel et al., 1980), and it is temporally related to cerebellar myelination (Reynolds and Wilkins, 1988; Kapfhammer and Schwab, 1994a; 
Huber et al., 2002) and to the decline of Purkinje axon regenerative potential (Gianola and Rossi, 2001). Together with the axonal sprouting and activation of growth-associated genes induced by functional neutralization of Nogo-A in adult Purkinje cells (Zagrebelsky et al., 1998; Buffo et al., 2000), these observations suggest that myelin-associated factors contribute to regulation of the developmental plasticity of Purkinje neurites. To test this hypothesis and to elucidate some of the mechanisms underlying the formation of the intracortical plexus, we examined the sprouting, growth, and pruning of Purkinje axon collaterals during postnatal development and investigated their interactions with oligodendrocytes. In addition, we asked whether the normal shaping of intracortical plexus can be achieved after oligodendrocyte removal or application of anti-Nogo-A antibodies. Our results indicate that Purkinje intracortical plexus develop according to stereotyped morphological patterns suggestive of the execution of an intrinsic growth program, but their typical distribution within precise cortical domains is disrupted when myelin development is prevented.

Parts of this paper have been published previously in abstract form (Gianola et al., 2002).

\section{Materials and Methods}

Experimental animals. The experiments were performed on Wistar rats (Charles River, Calco, Italy). Fifty rat pups from five littermates, killed at different postnatal ages from postnatal day 0 (P0) to P15 (three or four individuals per time point), were used to study the development of Purkinje axon intracortical plexus and cerebellar myelination. Forty-five rats from five additional littermates were used for experiments in which normal myelinogenesis was disrupted ( 5 '-azacytidine administration and anti-Nogo-A antibody injection), whereas two pregnant rats were used to prepare dissociated cultures of cerebellar cells. Finally, analysis of transplanted Purkinje cells was performed on material belonging to a previous study (Carletti et al., 2002). All surgical procedures were performed under deep general anesthesia obtained by intraperitoneal administration of ketamine (100 mg/kg; Ketavet; Bayer, Leverkusen, Germany) supplemented by xylazine ( $5 \mathrm{mg} / \mathrm{kg}$; Rompun; Bayer) or diazepam $(2.5 \mathrm{mg} / \mathrm{kg}$; Roche Molecular Biochemicals, Mannheim, Germany). In addition, rat pups (up to P8) were cryoanesthetized in melting ice. The experimental plan was designed according to National Institutes of Health guidelines and the Italian law for care and use of experimental animals (DL116/92) and approved by the Italian Ministry of Health and the Bioethical Committee of the University of Turin.

Disruption of cerebellar myelin development. To interfere with the development of cerebellar myelin, we used two different approaches. A first set of animals $(n=22)$ underwent daily subcutaneous injections of $5^{\prime}$ azacytidine ( $5 \mu \mathrm{g} / \mathrm{gm}$ of body weight, in saline) from P6 to P15. This modification of the method originally set up by Savio and Schwab (1989) (intraperitoneal injections from P0 to P15) was necessary to disrupt oligodendroglial development but to minimize effects on other proliferating cell populations (e.g., granule cell progenitors). Control rats $(n=5)$ received daily subcutaneous injections of vehicle (saline solution) during the same postnatal period. All these animals were killed at P15.

In another set of animals $(n=15)$, neutralizing antibodies against the myelin-associated neurite growth inhibitory protein Nogo-A were injected in the cerebellar parenchyma, as previously described (Zagrebelsky et al., 1998; Buffo et al., 2000). Deeply anesthetized P10 rat pups were fixed to a stereotaxic apparatus, and the cerebellar vermis was exposed by removing small fragments of the occipital bone. A glass micropipette, connected to a PV800 Pneumatic Picopump (WPI, New Haven, CT), was inserted $0.5 \mathrm{~mm}$ deep into the cerebellar parenchyma (vermal lobules $\mathrm{V}-\mathrm{VII})$, and $1.5-2 \mu \mathrm{l}$ of $11 \mathrm{C} 7$ anti-Nogo-A antibodies $(500 \mu \mathrm{g} / \mathrm{ml}$; kindly supplied by Novartis Pharma AG, Basel, Switzerland) was pressureinjected during 5-10 min. $11 \mathrm{C} 7$ is a monoclonal antibody directed against an 18-amino acid peptide of the Nogo-A-specific region, as previously described for the rabbit antiserum 472 (Chen et al., 2000). Control age-matched rats $(n=8)$ received similar injections of a mouse-anti- human IgG (heavy and light chain; Jackson ImmunoResearch, West Grove, PA). These animals were killed at P12 (three rats receiving antiNogo-A antibodies), P15 (eight rats injected with anti-Nogo-A and four with control antibodies), and P23 (four rats in either group).

Cultures of dissociated cerebellar cells. The preparation of dissociated cerebellar cell cultures was based on a protocol described by Hatten et al. (1998). Timed pregnant embryonic day 17 (E17) rat dams were deeply anesthetized (as above). The embryos were removed by cesarean section, collected in ice-cold PBS with $0.6 \%$ glucose (PBG), and immediately decapitated. The cerebella were dissected and collected in PBG. After incubation with trypsin (1\% in PBG; Sigma, St. Louis, MO) and DNase $(0.1 \%$; Sigma $)$ for $5 \mathrm{~min}$ at $37^{\circ} \mathrm{C}$, the tissue was mechanically dissociated to a single-cell suspension with fire-polished Pasteur pipettes in culture medium, supplemented with $10 \%$ horse serum. Culture medium was composed of Eagle's basal medium with Earles's salts (Invitrogen, Gaithersburg, MD) supplemented with glutamine ( $2 \mathrm{~mm}$; Invitrogen), glucose (32 mM), and penicillin-streptomycin $(20 \mathrm{U} / \mathrm{ml}$; Invitrogen). The cell suspension was diluted and plated on poly-D-lysine-coated glass coverslips ( $12 \mathrm{~mm}$ diameter, $5 \times 10^{4}$ cells per coverslip). After cells had attached (3-5 hr), the medium was changed into serum-free medium containing insulin $(5 \mu \mathrm{g} / \mathrm{ml})$, selenite $(5 \mathrm{ng} / \mathrm{ml})$, transferrin $(5 \mu \mathrm{g} / \mathrm{ml})$, and bovine serum albumin $(10 \mathrm{mg} / \mathrm{ml}$; all from Sigma). The cultures were maintained at $37^{\circ} \mathrm{C}$ in a humidified atmosphere with $5 \% \mathrm{CO}_{2}$ and fixed after 5,17 , or $20 \mathrm{~d}$ in vitro.

Transplanted Purkinje cells. To examine the axonal branching pattern of Purkinje cells grown in an unusual environment, we analyzed Purkinje cells heterotopically grafted to extracerebellar CNS regions. This material belonged to a previous study (Carletti et al., 2002), in which E12 embryonic cerebellar cells, taken from transgenic mice overexpressing enhanced green fluorescent protein (EGFP) under the control of the $\beta$-actin promoter, were transplanted in utero to the cerebral ventricles of E16 rat embryos. The examined material included $100-\mu \mathrm{m}$-thick vibratome sections from the brains of several recipient animals killed between P20 and P30 (for details, see Carletti et al., 2002).

Histological procedures. The animals were deeply anesthetized and perfusion-fixed with $4 \%$ paraformaldehyde in $0.12 \mathrm{M}$ phosphate buffer (200-1000 $\mathrm{ml}$ depending on the age). The brains were removed, postfixed overnight in the same fixative at $4^{\circ} \mathrm{C}$, and finally transferred to $30 \%$ sucrose in $0.12 \mathrm{M}$ phosphate buffer at $4^{\circ} \mathrm{C}$ until they sank. The cerebella were cut using a freezing microtome in several series of $30-\mu \mathrm{m}$-thick sagittal sections collected in Tris-buffered saline, $\mathrm{pH}$ 7.4.

One series of sections, used for morphometric analysis (see below), was first incubated in $0.3 \% \mathrm{H}_{2} \mathrm{O}_{2}$ in $\mathrm{PBS}$ to quench endogenous peroxidase. Then, the sections were incubated for $30 \mathrm{~min}$ at room temperature and overnight at $4^{\circ} \mathrm{C}$ with anti-calbindin D-28K (polyclonal, 1:3000; Swant, Bellinzona, Switzerland) diluted in PBS with $0.25 \%$ Triton X-100 added to $0.2 \%$ normal goat serum. Immunohistochemical staining was performed according to the avidin-biotin-peroxidase method (Vectastain ABC Elite kit; Vector Laboratories, Burlingame, CA) and revealed using $3,3^{\prime}$-diaminobenzidine $(0.03 \%$ in Tris- $\mathrm{HCl})$ as a chromogen. The reacted sections were finally mounted on gelatin-coated slides, air-dried, dehydrated, and coverslipped.

The other series of cerebellar sections was used for double immunofluorescence. They were first incubated overnight at $4^{\circ} \mathrm{C}$ with anticalbindin antibody (polyclonal, $1: 1500$, plus $0.2 \%$ normal goat serum in PBS and Triton X-100, as above) and revealed by $1 \mathrm{hr}$ of incubation at room temperature in a goat anti-rabbit IgG conjugated to fluorescein isothiocyanate (1:200 in PBS and Triton X-100 with $0.2 \%$ normal goat serum; Sigma). The sections were rinsed and incubated overnight at $4^{\circ} \mathrm{C}$ with the second primary antibody to reveal several oligodendrocytic markers: anti-myelin basic protein (MBP, monoclonal, 1:2000; Sternberger Monoclonals, Baltimore, MD), anti- neuroglycan 2 (NG2, polyclonal, 1:200; Chemicon, Temecula, CA), anti-Nogo-A (antibody 11C7, 1:10000; kindly supplied by Novartis Pharma AG), and anti-2', $3^{\prime}$ cyclic nucleotide $3^{\prime}$ phosphodiesterase (CNP, monoclonal, 1:500; Chemicon). These antibodies were diluted in PBS and Triton X-100 added to either normal horse serum or normal goat serum $(0.2 \%)$ depending on the species of the secondary antibody. Finally, the sections were incubated for $1 \mathrm{hr}$ in secondary biotinylated anti-mouse IgG or anti-rabbit IgG 


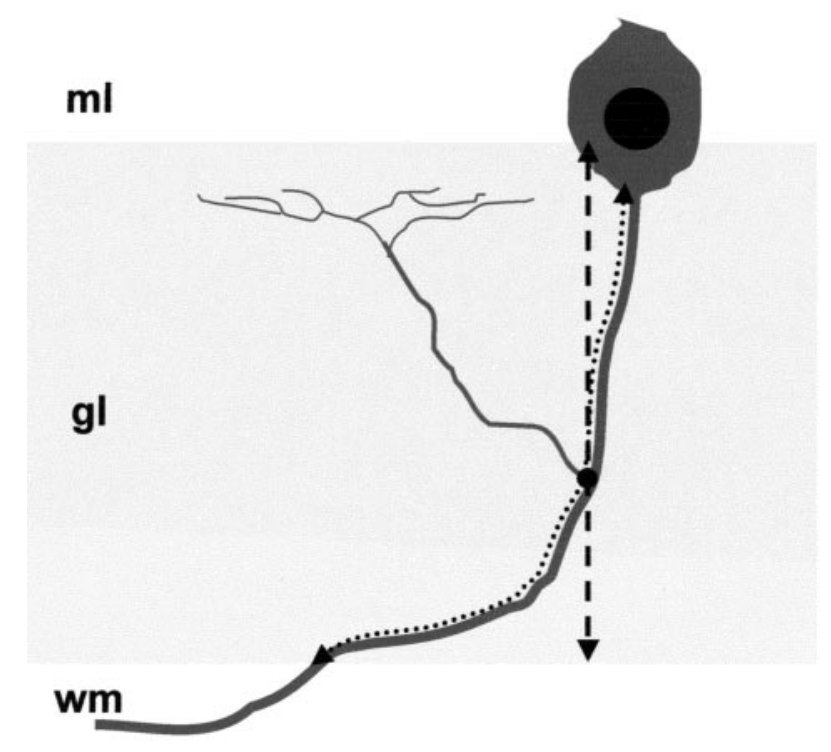

Figure 1. Evaluation of the position of branching points along Purkinje axons. We examined Purkinje axons whose course from the Purkinje cell body to the white matter (wm) could be followed in a single section. The course of these axons through the granular layer (gl, shaded area) was reproduced (dotted arrow), and the position of the branch origin (black dot) was marked. In addition, to evaluate the position of branching points relative to the granular layer depth, the thickness of the granular layer was estimated along a line perpendicular to the cerebellar surface (dashed arrow), which passed through the branch origin. ml, Molecular layer.

(1:200; Vector Laboratories) and then in streptavidin-Texas Red-X conjugate (1:200 in PBS and Triton X-100; Molecular Probes, Eugene, OR). After unbound Texas Red-X was washed off with PBS and Triton X-100, sections were coverslipped using a mixture of phosphate buffer, $\mathrm{pH}$ 7.27.4 , and glycerol.

Cerebellar cultures were fixed for 5-10 min in 4\% paraformaldehyde in $0.12 \mathrm{M}$ phosphate buffer and rinsed in PBS. They were immunostained for calbindin and revealed by peroxidase immunocytochemistry or immunofluorescence as described above.

Data analysis. The histological preparations were examined by means of a Zeiss (Oberkochen, Germany) Axiophot light microscope. Micrographs were taken by means of a Nikon (Mellville, NY) Coolpix 950 digital camera attached to the same microscope. The material was also examined with a Fluoview 300 confocal microscope (Olympus Optical, Hamburg, Germany). Digital images were processed with Adobe Photoshop 6.0 to adjust contrast and to assemble the final plates. Quantitative and morphometric evaluations were made using Neurolucida software (MicroBrightField Inc., Colchester, VT) connected to a Nikon E-800 microscope via a color CCD camera.

The morphometric evaluation of Purkinje axon collaterals during postnatal development was performed on calbindin-immunostained vermal sections of rat pups at different survival times between P6 and P15 (three or four animals per age). In these sections, at a high magnification with a $100 \times$ immersion oil objective, we counted the number of collateral processes originating from Purkinje axons whose course could be followed from the cell body to the axial white matter (100-150 axons were sampled at each age). The neurites were also subdivided according to their basoapical position along cerebellar lobules (see Fig. 3C). Statistical evaluations on the changes of primary Purkinje collateral branches was performed by ANOVA.

The axons sampled from P8 and P15 cerebella ( $n=106$ and 157, respectively) were reproduced by the Neurolucida software (MicroBrightField), and the position of branching points along the course was marked (Fig. 1, dotted arrow). In addition, to determine the position of branching points relative to the granular layer depth, the thickness of the granular layer was estimated along a line perpendicular to the cerebellar surface, passing through the branch origin (Fig. 1, dashed arrow). Because the thickness of the granular layer is not uniform along the cere- bellar cortex, the position of branching point is represented in Figure 4, A and $B$, relative to the normalized extension of the layer.

A similar analysis was performed on calbindin-immunolabeled Purkinje cells from dissociated cultures after 17-20 d in vitro. Only isolated Purkinje cells located at the periphery of the culture with no or minimal contact with other cells were examined. In this case, the whole axon was reproduced, including terminal arbors and collateral branches $(n=109$ from six cultures). The latter were identified according to the following criteria: (1) they were thinner than the parent neurite; (2) they spread at right angles from the axon shaft; and (3) they terminated in poorly extended terminal networks (see Fig. 4D,E). All the other processes emanating from the axon shaft, fine filopodia $<30 \mu \mathrm{m}$ long, were not considered.

Finally, we examined 73 transplanted Purkinje cells, located in different extracerebellar regions of the recipient brain, whose axon could be followed for $>200 \mu \mathrm{m}$ through a single $100-\mu \mathrm{m}$-thick vibratome section. The whole axon segment was reproduced, and branching points were marked. In all the different conditions, the values obtained from Purkinje axon-bearing collateral branches are illustrated in the graphs of Figure 4 , in which single neurites are plotted on the $y$-axis, and the position of branching points is reported on the $x$-axis. Statistical analysis was performed by Student's $t$ test.

Morphometric analysis to quantify the structural changes of recurrent collateral plexus in $5^{\prime}$-azacytidine- and in Nogo-A-treated cerebella was performed following a previously established method (Buffo et al., 2000). For each animal, three calbindin-immunolabeled vermal sections were selected and subdivided into "treated" and "control" regions. In 5'azacytidine-injected animals $(n=5)$, because of the nonsynchronous development of cerebellar cortex (see Results), myelination was particularly delayed at the later maturing apex of cortical lobules, whereas in basal regions, myelinogenesis appeared unaffected at the time of examination (see Fig. $7 A, B$ ). Indeed, $5^{\prime}$-azacytidine treatment was only started at P6; it is likely that many oligodendrocyte precursors destined to basal lobule portions are already postmitotic at this age. Thus, in these animals, treated regions were the apical portions of lobules V-VII, whereas basal regions of the same lobules were taken as an internal control (the approximate positions of these areas are illustrated in Fig. $8 \mathrm{~A}$ ). The same regions were analyzed in the cerebella of age-matched (P15) vehicle-injected animals $(n=5)$. The analysis was restricted to these lobules to sample axons from comparable regions in control and treated animals.

In the sections from cerebella receiving antibody injections, treated regions were the distal portions of dorsal vermal lobules (V-VII), located close to the injection site, whereas distal regions of ventral vermal lobules (I-III), distant from the injection site, were taken as the internal control (the approximate positions of these areas are illustrated in Fig. $8 B$ ) (Buffo et al., 2000). Antibody injections were made at P10, and the examined animals were killed at P15 (five animals injected with antiNogo-A antibodies and four rats receiving control antibody injections) or at P23 (four animals in each group).

Morphometric measurements of Purkinje axons were performed on three sagittal sections of the cerebellar vermis from each animal (Buffo et al., 2000). In each section, we sampled one area in treated and one in control regions by superimposing a $155 \times 255 \mu \mathrm{m}$ square. On the whole, three treated and three control areas were sampled for each animal. The selected areas encompassed the whole granular layer depth and contained only minimal portions of the Purkinje cell layer or axial white matter. All the anti-calbindin-immunostained Purkinje axon segments present within such areas were reproduced using the Neurolucida software (MicroBrightField Inc.) with a $20 \times$ objective, corresponding to $750 \times$ magnification on the computer screen. Each labeled axon segment or branch was reproduced as a single profile. From these reproductions, the software calculated the number of axon profiles, the total length of all the reproduced segments, and the number of times that the axons crossed a $25 \times 25 \mu \mathrm{m}$ grid superimposed on the selected area. The data from the different areas in the three sections sampled from each cerebellum were averaged to obtain values for every individual animal ( $n=5$ for $5^{\prime}$ azacytidine experiments and P15 anti-Nogo-A injected animals; $n=4$ for P23 anti-Nogo-A and P15 and P23 control antibody injections). These values were used to prepare the histograms of Figure 8 (where 
mean \pm SD is reported) and for statistical analysis performed by Student's $t$ test.

Finally, to assess whether anti-Nogo-A antibodies induced oligodendrocyte death, we estimated the fraction of myelinated Purkinje axons in P15 rats treated with anti-Nogo-A antibodies $(n=5)$ and control antibodies $(n=$ $4)$ and in a set of intact animals $(n=4)$. From each case, we sampled 100-120 Purkinje axon profiles in the axial white matter of vermal lobules V-VII in sections double-labeled for calbindin and MBP. For each axon, we determined whether it was associated with an MBPimmunostained oligodendroglial process. Neuritic profiles not covered or partially covered by MBP-labeled processes were classified as unmyelinated. Statistical analysis was performed by Student's $t$ test.

\section{Results}

Growth and remodeling of Purkinje axon collateral branches

The formation of Purkinje axon intracortical plexus was investigated in calbindinimmunostained cerebella of rat pups during the first 2 postnatal weeks. The maturation of Purkinje cells and other cortical elements is not synchronous throughout the whole cerebellum but proceeds in a progressive manner along the mediolateral, caudorostral, and proximodistal axes (Inouye and Murakami, 1980; Altman and Bayer, 1985, 1997). Consequently, although our observations were restricted to the vermal cortex, there was a clear time lag between the maturation of Purkinje neurons situated at the lobule apex and those located at the base in the depth of the fissures (see Fig. 3C). For the sake of simplicity, in the following description, specific developmental stages are related to precise postnatal ages referring to Purkinje cells located in the medium region of cortical lobules (see Fig. $3 C$ ), ontogenetic events being more advanced toward the base and delayed toward the apex.

Consistent with previous reports (Eisenman et al., 1991), the corticofugal Purkinje cell projection was already established at birth, and strongly stained axons could be followed up to their terminal fields in the deep cerebellar nuclei. During early postnatal days (P0-P4), Purkinje axons formed a dense network in the nascent internal granular layer (Fig. $2 \mathrm{~A}$ ), making it difficult to distinguish single neurites or branches. Thus, although the development of collateral branches may begin at a younger age, we decided to restrict our analysis from P5 onward when, because of the progressive expansion of the internal granular layer, it was possible to examine individual Purkinje axons.

At P5, thin Purkinje neurites originated from the basal perikaryal pole and ran across the granular layer. Along their intracortical segment, most of these axons displayed focal enlargements of different sizes and shapes, from moderate thickenings to large swellings (Fig. $2 B-E$ ). The latter often appeared to

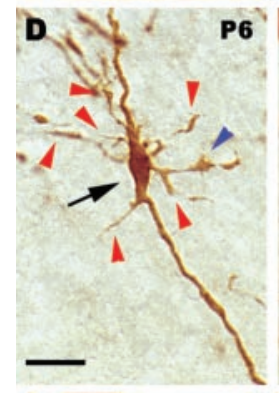

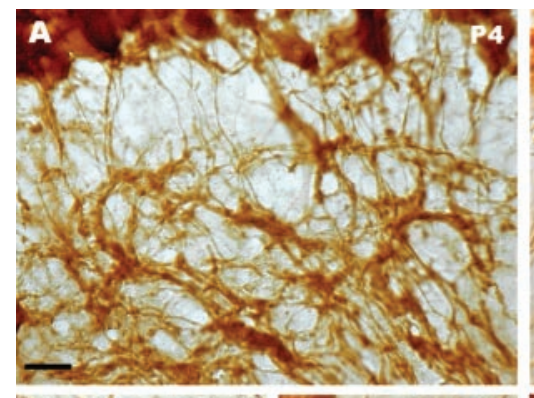
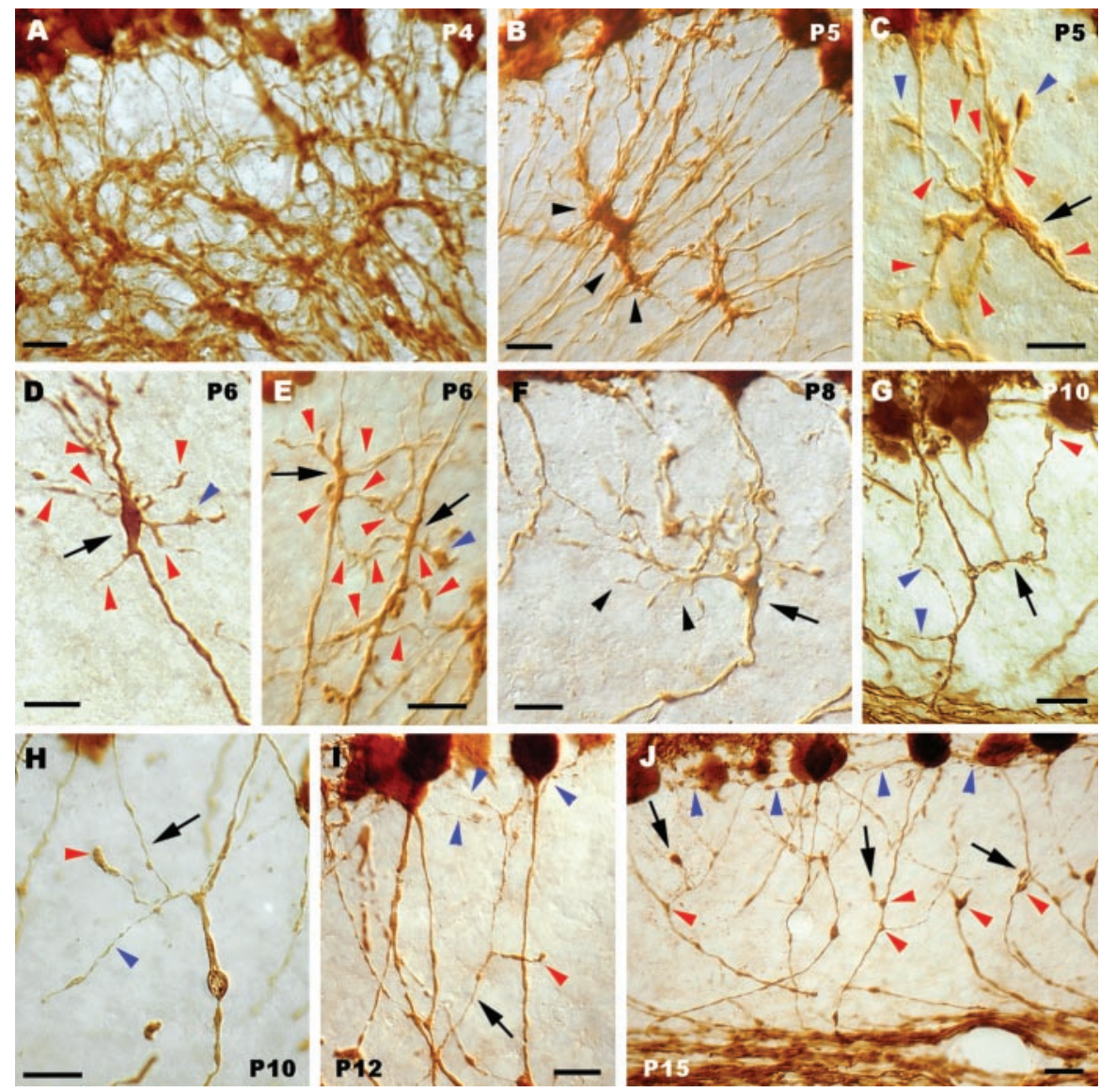

Figure 2. Sprouting, growth, and pruning of Purkinje axon collateral branches. A, Dense meshwork formed by calbindinimmunolabeled Purkinje axons in the nascent granular layer during the very first postnatal days. Arrowheads in $B$ point to a clump rkinje axon swellings in the granular layer. $(-E$, Thickened or swollen segments (arrows) of individual Purkinje axons, from . win granular layer, giving off several second-order ramifications. The arrow in $G$ indicates another collateral branch same corticofugal axon, are indicated by blue arrowheads. $H$, Thin collateral branch (arrow) ascending through the granular layer; a secondary ramification of this process ends with a large varicosity (red arrowhead). The blue arrowhead points to another process from the same intracortical plexus that ends with a small bouton. The thin branch shown in / (arrow) courses through the granular layer and terminates with some fine varicose chains (blue arrowheads) confined to the vicinity of the Purkinje cell layer; deeper in the granular layer, a shorter process belonging to the same plexus bears a terminal club (red arrowhead). Several presumptive pruning processes terminating with round clubs are indicated by arrows in J. Also note that the enlarged segments along the fugal neurites have disappeared, leaving small triangular varicosities (red arrowheads), whereas the fine terminal branches (some indicated by blue arrowheads) are confined to the most superficial portion of the granular layer. Anti-calbindin immunolabeling is shown in all panels. Postnatal ages are indicated on the micrographs. Scale bars: $A, B, G, J, 20 \mu \mathrm{m} ; C-F, H, I, 10 \mu \mathrm{m}$.

adhere to each other in clumps formed by different converging axons (Fig. $2 \mathrm{~B}$ ). The analysis of individual neurites, well separated from their neighbors, revealed that several new processes, including fine filopodia, short sprouts, and longer profiles with tiny growth cones, originated from the enlarged segments (Fig. $2 C-E)$. Such an active sprouting of collateral branches was evident up to P8-P10. The outgrowing processes, which appeared progressively more complex and ramified, spread throughout the granular layer (Fig. $2 F$ ), but in many instances, they were clearly oriented toward the overlying Purkinje cell layer (Fig. 2G).

The terminal varicose chains of the infraganglionic plexus (the supraganglionic one, in the lower molecular layer, was obscured in our preparations by the staining of Purkinje cell dendrites) gradually developed during the following days. At the same time, however, Purkinje axons displayed novel morphological features, suggestive of a different developmental phase (Fig. $2 \mathrm{H}-\mathrm{J}$ ). The 

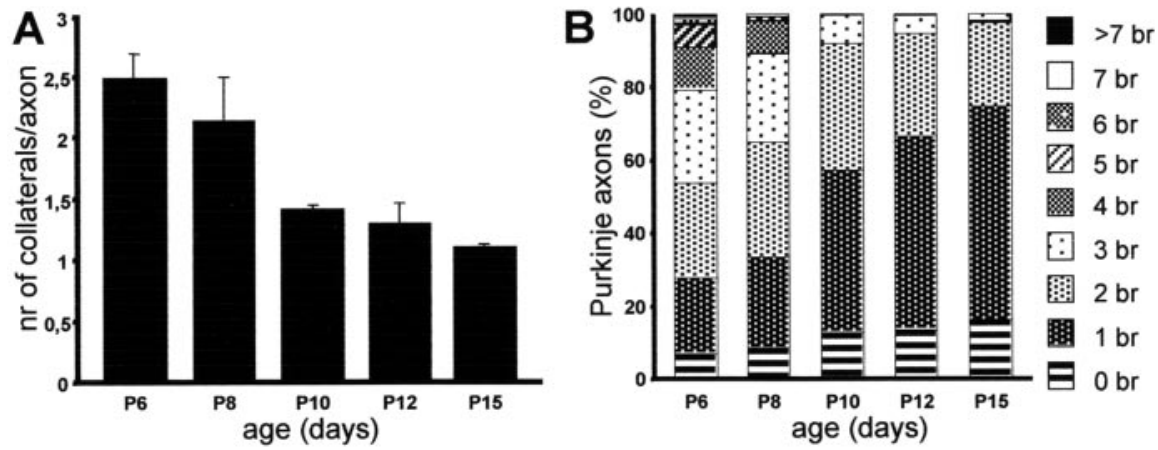

at P15, 97.5\% of Purkinje axons had two or fewer branches. Interestingly, at all ages we encountered a small but consistent fraction of Purkinje neurites $(6.8 \%$ at P6 and $16.2 \%$ at P15) with no collateral branches, indicating that a subset of Purkinje cells in the adult cerebellum lacks recurrent intracortical plexus.

\section{Cell-autonomous mechanisms in the development of Purkinje axon collateral branches}

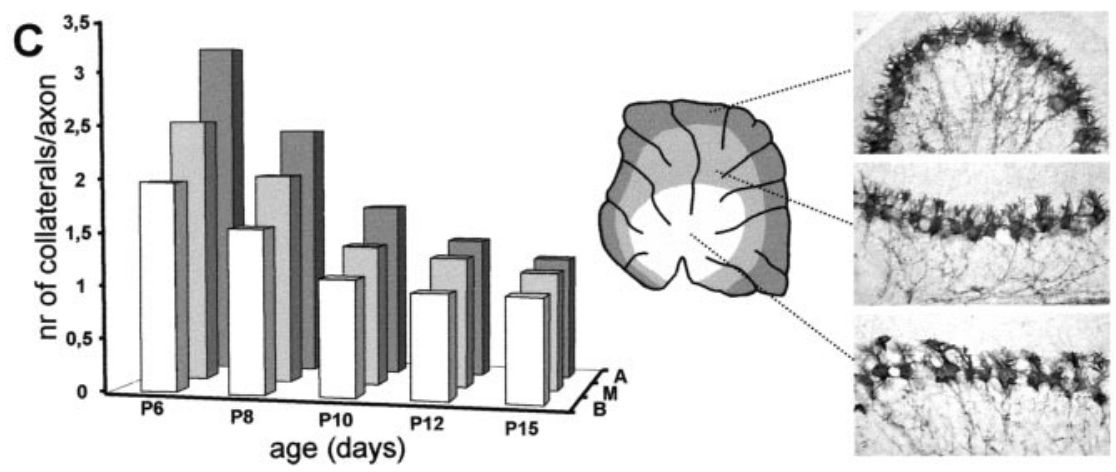

Figure 3. Retraction of Purkinje axon collateral branches during postnatal development. $A$, Mean number of first-order collateral branches $\pm S D$ issued by stem Purkinje axons at different postnatal ages. $B$, Normalized frequency distribution of the number of collateral branches (br) on individual Purkinje axons during the same period. C, Time course of collateral branch withdrawal in separate samples of Purkinje axons from apical (A), medium (M), or basal (B) regions of cortical lobules (indicated by corresponding shadowing on the diagram). The micrographs, all taken from the same cerebellar section at P8, show the nonsynchronous maturation of Purkinje cells located at different basoapical positions along the same cortical lobule (lobule VI). nr, Number.

large axon swellings gradually disappeared, leaving tiny triangular-shaped varicosities situated at branching points (Fig. 2J) (Gravel et al., 1986). Collateral branches issued from corticofugal neurites were less frequent and appeared as thin ramified processes ascending through the granular layer. In addition, numerous Purkinje axon profiles, including both primary branches (Fig. $2 J$ ) and second- and third-order ramifications in the deep granular layer (Fig. $2 \mathrm{H}, \mathrm{I}$ ), terminated with characteristic roundshaped boutons. Similar terminal clubs have been associated with axon-pruning phenomena (Acebes and Ferrus, 2000), such as physiological remodeling at the neuromuscular junction (Riley, 1981; Bernstein and Lichtman, 1999) or axonal retraction after target loss in the adult (Rossi et al., 1993). Hence, we interpreted these structural features of Purkinje axons as a morphological correlate of the withdrawal of supernumerary branches. The mature morphology of Purkinje axon collaterals was essentially achieved at the end of the second postnatal week, with sparse ascending branches and fine networks of varicose chains, strictly confined in the upper granular layer (Fig. $2 \mathrm{~J}$ ).

The progressive pruning of Purkinje intracortical plexus was confirmed by quantitative estimations of the number of firstorder ramifications issued by corticofugal neurites (Fig. $3 A-C$ ). The mean number of branches (Fig. $3 A$ ) decreased from $2.48 \pm$ 0.21 (mean $\pm \mathrm{SD}$ ) at P6 to $1.11 \pm 0.03$ at P15 (ANOVA, $f_{(4,15)}=$ $34.3 ; p<0.001)$. The same trend was also observed when axons from different proximodistal positions along the cerebellar lobules were examined separately, although, as expected, the maturation process was more advanced in basal than in apical regions (Fig. 3C). The frequency distribution of collateral branches shifted accordingly to lower values with increasing ages (Fig. 3B);
The origin of Purkinje collateral branches in vivo is related to the distance from the cell body but not to the position in the granular layer

To investigate the cellular mechanisms underlying the interstitial sprouting of Purkinje axon collaterals, we first asked whether the branching site was related to the distance from the perikaryon or to the position in the granular layer. The latter instance would imply the intervention of local branch-promoting cues positioned in a specific region of the granular layer, whereas the former would be suggestive of an intrinsically programmed growth pattern. We sampled Purkinje axons, whose course from the cell body to the white matter could be followed in a single section, and determined the position of branching points in relation to the granular layer depth or the parent cell body (see Materials and Methods; Fig. 1). As shown in Figure $4, A$ and $B$ (referring to P8 and P15, respectively), branching points were uniformly distributed throughout the whole thickness of the granular layer, except for the upper $10 \%$ (just below the Purkinje cell layer), where no branching points occurred. When the distance from the cell body was considered (Fig. 4C,D), all branching sites were localized within the first 150-200 $\mu \mathrm{m}$ of neuritic length. The mean distance was significantly shorter at P8 (66 $\pm 3.16 \mu \mathrm{m}$, mean \pm SD, 106 axons $)$ than at P15 (103.6 $\pm 12.4 \mu \mathrm{m}, 157$ axons; Student's $t$ test, $p<0.001)$, indicating that during this period, the position of branching points was progressively displaced.

The results of this analysis indicate that collateral branches originate from a restricted segment of the Purkinje axon. Nevertheless, they do not show that the position of branching point is dependent on the distance from the cell body. Indeed, the observed distance range fairly corresponds to the average thickness of the granular layer; hence, it could be also attributed to extrinsic cues distributed over the whole extension of the layer. To rule out this possibility, we sampled axons whose course through the granular layer (Fig. 1, dotted arrow) was longer than $200 \mu \mathrm{m}$ in cortical regions where the thickness of this layer (Fig. 1, dashed arrow) was $<200 \mu \mathrm{m}$. As shown in Figure $4 E$, also for these axons, the position of branching points was never farther than $200 \mu \mathrm{m}$ from the cell body, even if the neurite segment coursing through the granular layer was 100-200 $\mu \mathrm{m}$ longer. The mean distance was $106.8 \pm 4.2 \mu \mathrm{m}$ (72 axons), close to the value obtained from the whole P15 sample (see above). Thus, collateral branches are issued from a specific region of the Purkinje axon (within 150-200 $\mu \mathrm{m}$ from the soma) irrespective of the location 
in the depth of the granular layer, suggesting that the position of branching points is determined by cell-autonomous mechanisms rather than extrinsic cues.

\section{Branching pattern of Purkinje axons} grown into unusual environments To further corroborate this conclusion, we examined the branching pattern of Purkinje axons in two different conditions in which they developed in an unusual environment. We first investigated the pattern of axon growth of Purkinje cells dissociated at E17 and maintained in culture for several weeks. The analysis was restricted to isolated Purkinje cells at the periphery of the culture dish with no or minimal contact with other cells. At $5 \mathrm{~d}$ in vitro (Fig. 5A-C), Purkinje cells displayed thick neurites that ended with prominent growth cones, sometimes breaking in two or three branches to form the terminal arbor. Most interestingly, however, many of such axons displayed large lamellipodialike swellings, situated well behind the leading growth cone. Numerous thin filopodia (Fig. 5A,B) and a number of longer and thicker processes ending with small growth cones (Fig. 5C) radiated from such enlargements. At $17-20 \mathrm{~d}$ in vitro (Fig. $5 D-F$ ), Purkinje axons displayed well developed terminal arbors, made of several long processes, originating from the bifurcation of the stem neurite. Lamellipodia-like swellings were no more visible along the axon, and in many cases (34 of 109 Purkinje cells), there were no ramifications along the neuritic segment proximal to the terminal arbor (Fig. $5 F)$. Nevertheless, the majority of Purkinje axons did show some clear-cut collateral branches, identified by a number of distinctive features: (1) they were thinner than the parent neurite; (2) they spread at right angles from the axon shaft; and (3) they terminated in poorly extended terminal networks (Fig. 5D,E).

The origin of collateral branches was always within the first $150 \mu \mathrm{m}$ from the cell body (Fig. $4 F$ ). The mean distance, $61.5 \pm 12.7 \mu \mathrm{m}$ (mean $\pm \mathrm{SD}, 75$ axons), was remarkably similar to that observed at $\mathrm{P} 8$ in vivo. Thus, Purkinje cells grown in vitro, with minimal contact with other cerebellar cells, develop a typical pattern of axon growth, similar to that seen in vivo, with a stem neurite bearing a large terminal field and a few collateral branches, issued along a well defined axon segment.

To further elucidate whether this peculiar axon phenotype can be expressed in other unusual environments, we examined the neurites of Purkinje cells taken from E12 embryonic mouse cerebella and heterotopically transplanted to E16 rat embryos in utero (Carletti et al., 2002). In this condition, we analyzed Purkinje cells ectopically located in several extracerebellar regions,
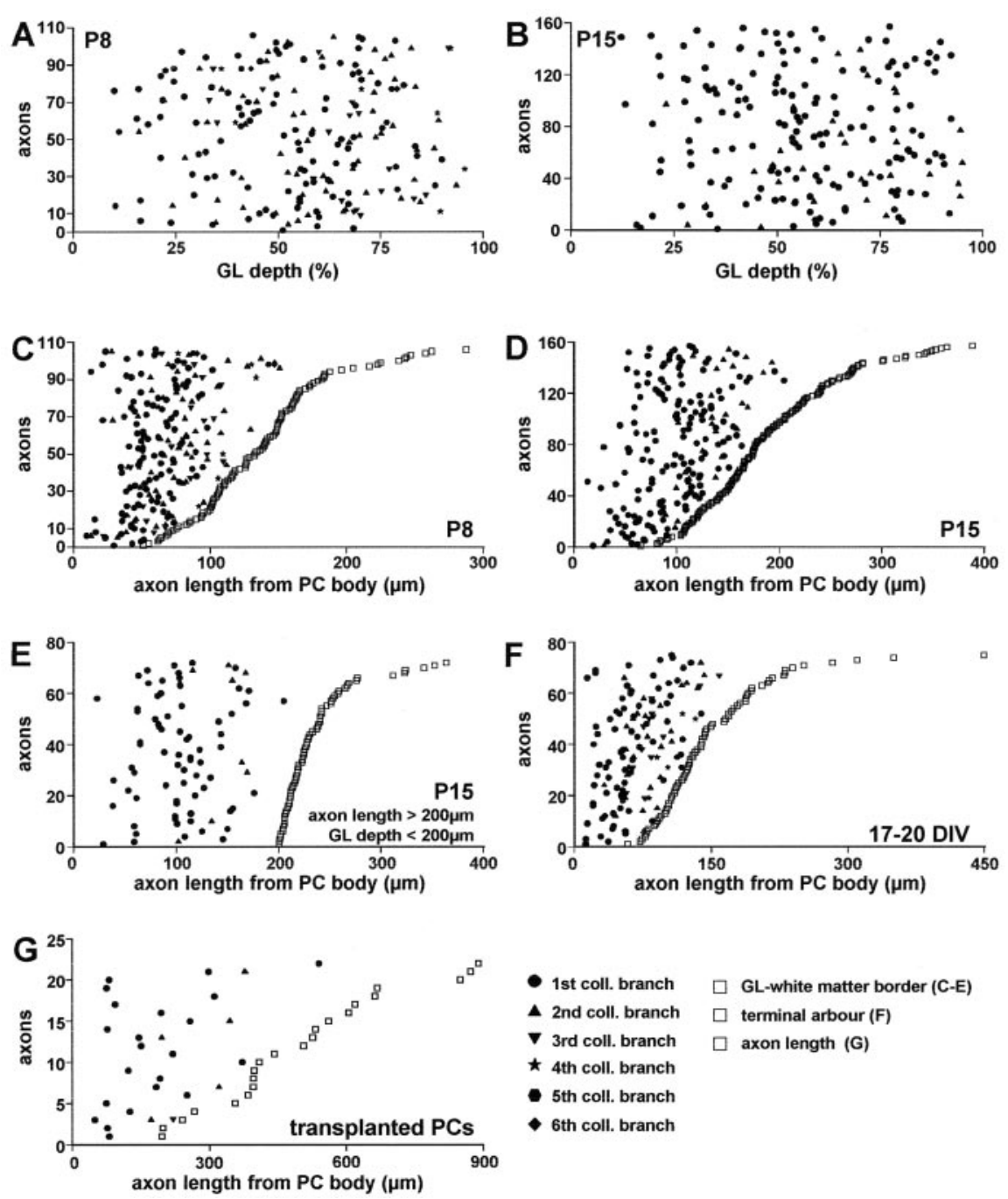

Figure 4. Morphometric evaluation of the position of Purkinje axon collateral branching points. In all graphs, the sampled Purkinje axons are represented individually along the $y$-axis; for each axon, the measured length and the position of branching points are represented along a line parallel to the $x$-axis. Collateral branches are numbered according to their origin along the neurite and represented by different solid markers (bottom right graph), the first branch being the nearest to the Purkinje cell perikaryon. In $A, B$, the position of branching points is plotted versus the normalized thickness of the granular layer (GL; 0 corresponds to Purkinje cell layer, 100 to white matter) at P8 and P15, respectively. (-G, Position of branching points along axon length: 0 on the $x$-axis corresponds to the origin of the neurite from the Purkinje cell (PC) body; open squares indicate the length of the segment measured for each axon in the different conditions (see below). Individual axons are ordered along the $y$-axis according to the length of this segment. In $C-E$, open squares indicate the length of the axon segment from the cell body to the granular layer-white matter border; the other markers indicate the position of collateral branches along each axon. C, D, Position of branching points at $\mathrm{P} 8$ and $\mathrm{P} 15$. E, Same analysis performed on a sample of $\mathrm{P} 15$ axons, which run through a granular layer $<200$ $\mu \mathrm{m}$ thick with a course longer than $200 \mu \mathrm{m}$. F, Position of branching points estimated for Purkinje cells grown 17-20 din vitro (DIV); open squares represent the distance from the cell body to the first bifurcation of the terminal arbor. G, Position of branching points in Purkinje cells transplanted to extracerebellar CNS regions; open squares indicate the length of the axon that could be followed through a single $100-\mu \mathrm{m}$-thick section.

whose axons could be followed for at least $200 \mu \mathrm{m}$ through a single $100-\mu \mathrm{m}$-thick vibratome section. Although $70 \%$ of the sampled Purkinje cells did not bear any ramification along the examined axon segment, in several instances we did observe typical recurrent collateral branches with morphological features similar to those observed in the cerebellum in vivo (Fig. 5G-I). Most of these branches also originated a few hundred micrometers from the soma, but in some cases they were more distant, up to $500 \mu \mathrm{m}$ (Fig. $4 G$ ). Nevertheless, all the examined axons bore only one or two (occasionally three) collateral branches with typical morphological features (Fig. 5G-I). Altogether, these obser- 


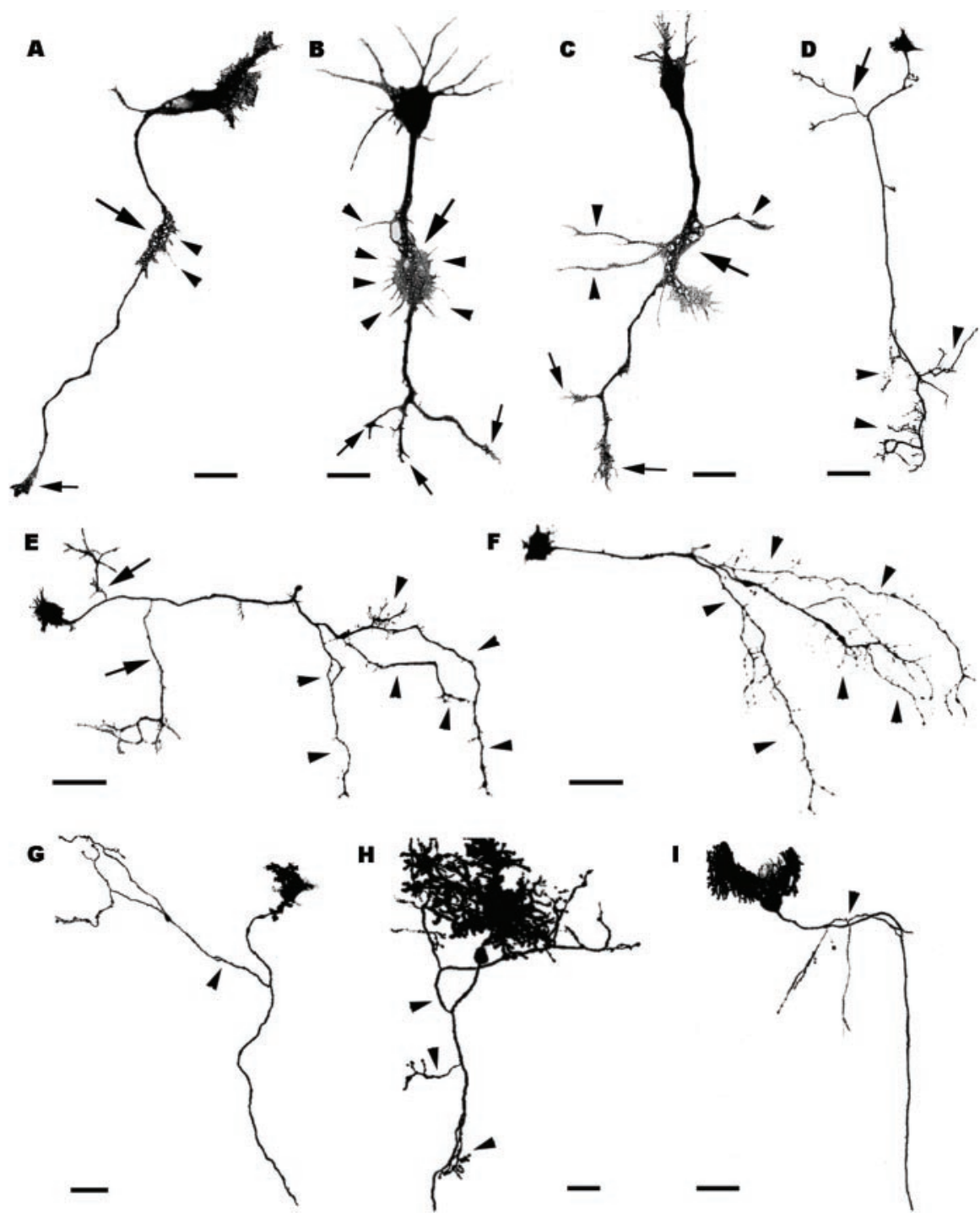

Figure 5. Axon branching pattern of Purkinje cells grown in vitro $(A-F)$ or transplanted to extracerebellar CNS regions $(G-l)$ $A-C$, Three Purkinje cells after $5 \mathrm{~d}$ in vitro; large arrows point to the lamellipodia-like swellings located along the axons, behind the leading growth cones (small arrows). Thin filopodia ( $A, B$, arrowheads) or longer processes ( $C$, arrowheads) sprout from such swellings. $D-F$, Purkinje cells after $20 \mathrm{~d}$ in vitro; arrowheads indicate terminal arbors, whereas arrows in $D, E$ point to collateral branches. Note that the Purkinje cell in F has no collateral ramifications. G-I, Transplanted Purkinje cells grown in extracerebellar CNS regions ( $G$, diencephalon; $H$, mesencephalon; I cerebral cortex); arrowheads point to collateral ramifications. All panels are confocal stacks of calbindin-immunofluorescent $(A-F)$ or EGFP-expressing (G-I) Purkinje cells. Scale bars: $A-C, 20 \mu \mathrm{m} ; H, 30 \mu \mathrm{m}$; $D-G, I, 50 \mu \mathrm{m}$.

vations indicate that the Purkinje axons develop according to a stereotyped pattern that is substantially maintained in a foreign environment.

Myelin formation in the cerebellar cortex and its relationship with the development of Purkinje cell collateral branches

To elucidate the role played by myelin-associated factors in the maturation of Purkinje cell intracortical plexus, we first examined the relationship between outgrowing collateral branches and oligodendrocytes during postnatal cerebellar development. In line with previous reports (Reynolds and Wilkins, 1988; Kapfhammer and Schwab, 1994a), myelin formation, as visualized by anti-MBP staining, started at the end of the first postnatal week (P6) from the central white matter and progressed toward the periphery during the following days (Fig. 6A-D). Between P6 and $\mathrm{P} 10, \mathrm{MBP}$-stained profiles gradually advanced along the axial white matter of cortical lobules (Fig. $6 A, B)$. Labeled processes first appeared in the granular layer at P10-P12 (Fig. 6C), and myelination in this layer was almost complete by P15 (Fig. 6D), although the density of labeled profiles increased further during the following days (data not shown). Purkinje axons are thus myelinated in a retrograde manner starting at $\sim$ P6 from the corticofugal branch in the white matter, whereas the intracortical neuritic segments are covered by myelin sheaths after P10.

To investigate the interactions between Purkinje axons and oligodendrocytes during postnatal development, we performed additional double labeling for calbindin and the glial precursor marker NG2 (Dawson et al., 2000) or the myelinassociated neurite growth inhibitor Nogo-A (Chen et al., 2000). As previously reported (Levine et al., 1993), high numbers of NG2-positive cells, characterized by several branched processes, were already present in the granular layer during the first postnatal week. In many instances, such processes were in close relationship with Purkinje axons or outgrowing collateral branches (Fig. 6E,F), suggesting that Purkinje neurites interact with presumptive immature oligodendrocytes during the phase of collateral branch sprouting and growth.

During the first postnatal week, Nogo-A antibodies did not stain oligodendrocytic processes, whereas Purkinje cell bodies and dendrites, but not axons, displayed clear labeling that gradually faded out during the following days (Fig. $6 G, H)$. Faint Nogo-A labeling in the central white matter was first detected at $\mathrm{P} 8$ (Fig. $6 H$ ), but clearly stained oligodendrocyte cell bodies or processes became evident at P10 (Fig. 6I) (Huber et al., 2002). Thereafter, Nogo-A-positive cells and processes radiated into the granular layer twining around Purkinje axons (Fig. $6 J)$. By P15, intensely labeled oligodendrocytes with several processes apposed to Purkinje neurites appeared throughout the granular layer (Fig. $6 K, L$ ). Thus, myelination of intracortical Purkinje axons and, most notably, expression of Nogo-A occur after $\mathrm{P} 10$, at the time when the bulk of neuritic pruning takes place.

Disruption of myelin formation interferes with the structural remodeling of Purkinje axon collateral branches

To assess whether myelination contributes to the structural remodeling of Purkinje cell intracortical plexus, we examined the morphology of recurrent collateral branches in experimental conditions in which normal myelin development was prevented. In a first series of experiments, we killed oligodendrocyte precursors by systemic administration of the antimitotic agent 5 'azacytidine between P6 and P15 (Savio and Schwab, 1989). Be- 
cause granule cell development could also be affected by this treatment, we injected 5 '-azacytidine subcutaneously for a restricted period (see Materials and Methods) to interfere with myelin formation without disrupting the global maturation of the cerebellar cortex. Indeed, our treated cerebella did not show the typical alterations associated with granule cell loss, such as hyperfoliation, disorganization of the Purkinje cell monolayer, or abnormal Purkinje cell dendrites (Sotelo, 1990; Ji and Hawkes, 1996; Altman and Bayer, 1997). Because of this mild treatment, however, myelin formation was only delayed, particularly at the apical regions of cortical lobules, where oligodendrocytic maturation occurs later (e.g., Fig. $6 A-D)$. At P15, basal regions displayed a pattern of myelination similar to that seen in intact animals, and Purkinje axon collaterals were already confined to the upper granular layer (Fig. 7A). In contrast, in the apical regions, MBP- or Nogo-A-positive profiles were sparse, and numerous calbindin-immunolabeled neurites covered the deep granular layer, with a clear reciprocal distribution between oligodendroglial profiles and axonal processes (Fig. 7B). Quantitative analysis of Purkinje axon changes was performed by comparing a number of morphometric parameters measured in the basal and apical regions of vermal lobules V-VII from P15 5'-azacytidine-treated rats $(n=5)$ and age-matched animals that received vehicle injections $(n=5)$. As shown in Figure $8 A$, no significant differences were observed in the basal lobule portions of treated and control animals, whereas in the apical regions there was a clear increase in the number of axonal profiles (Student's $t$ test, $p=0.016)$, total length $(p<0.001)$, and density $(p<0.001)$. Thus, in those cortical regions where myelin formation was effectively disrupted, the maturation of Purkinje intracortical plexus was strongly altered, and numerous processes remained in the deep granular layer.

To further elucidate the role of myelin-associated molecules in the developmental plasticity of Purkinje axons, we injected anti-Nogo-A antibodies or mouse anti-human IgGs as a control in the cerebellar parenchyma of P10 rats. At P15, oligodendroglial cell bodies and processes, which were already numerous in the granular layer of intact or control antibody-treated animals, were sparse in the cortical lobules neighboring anti-Nogo-A injection sites (Fig. 7C-E). The latter lobules were characterized by numerous calbindin-immunolabeled profiles distributed over the whole granular layer (Fig. 7C,D), including those regions where some oligodendrocytes were present (Fig. 7E). Quantitative analysis showed a significant increase of all morphometric parameters in cortical folia surrounding anti-Nogo-A injection sites compared with similar regions from cerebella treated with con-
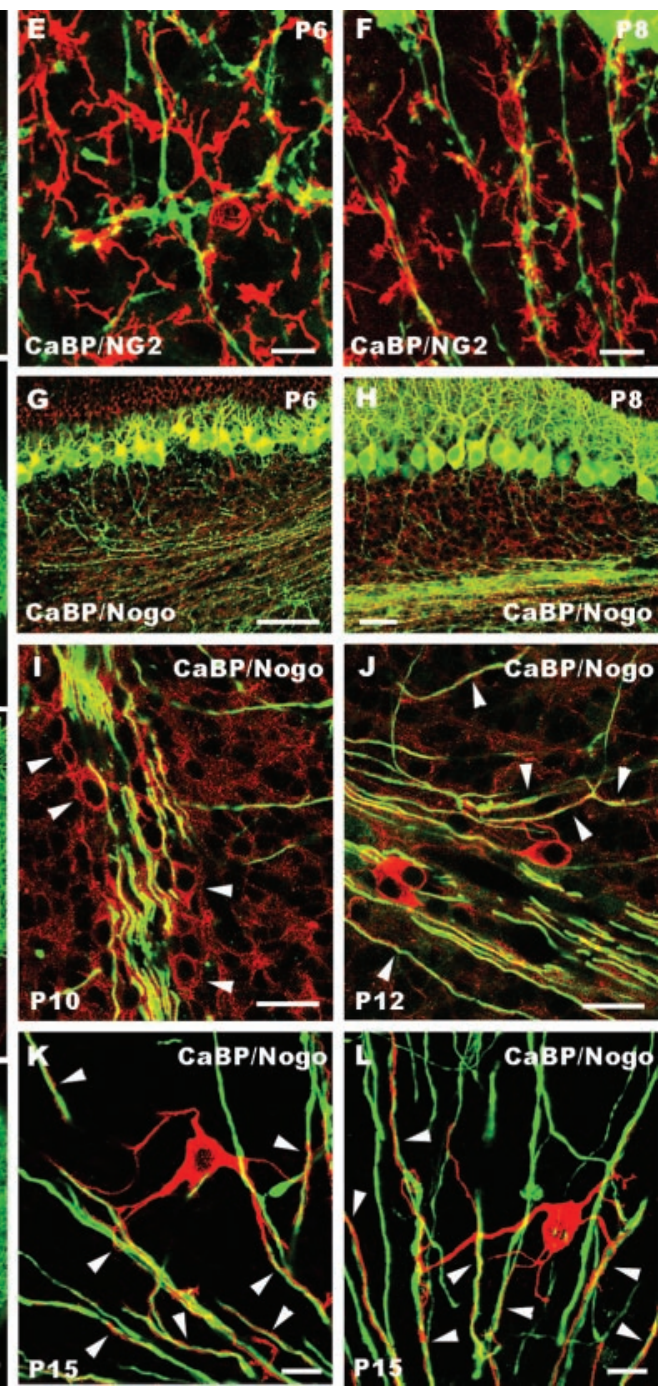

Figure 6. Postnatal development of cerebellar myelin. $A-D$, Survey images double labeled for calbindin (CaBP, green) and MBP (red) showing the development of Purkinje axon myelination, which progresses in a retrograde manner from the axial white green) and presumptive oligodendrocyte precursors labeled by anti-NG2 antibodies (red). $G-L$, Confocal images taken from cerebellar sections double-labeled for calbindin (green) and Nogo-A (red). Note the progressively fading somatodendritic staining ogo-A-positive oligodendrocytes (I, arrowheads) appear at P10. From P12 onward $(J-L)$, strongly stained oligodendrocytes are present in the granular layer, with long processes (arrowheads) twining around Purkinje axons. Postnatal ages are indicated on the micrographs. Scale bars: $E, F, K, L, 10 \mu \mathrm{m} ; I, J, 20 \mu \mathrm{m} ; D, H, 50 \mu \mathrm{m} ; A-C, G, 100 \mu \mathrm{m}$.

trol antibodies (Fig. $8 B$; number of axonal profiles, Student's $t$ test, $p<0.001$; total length, $p=0.007$; density, $p=0.008)$. In contrast, no differences were found when regions distant from the injection sites were compared (Fig. $8 \mathrm{~B}$ ).

The reduced amount of oligodendrocytes in the granular layer of anti-Nogo-A-treated cerebella could suggest that the effect on Purkinje axons was attributable to glial cell loss rather than neutralization of Nogo-A. However, both in P15 animals and in three additional animals killed at P12, we found no evidence for myelin degeneration or axonal damage, except for a restricted region in the immediate vicinity of the cannula track. Furthermore, the fraction of myelinated Purkinje axons in the axial white matter of the lobules surrounding the injection site was equivalent in antiNogo-A-treated rats $(90.5 \pm 2.4 \%$, mean $\pm \mathrm{SD} ; n=5)$, in those injected with control antibody $(90.8 \pm 2.3 \% ; n=4)$, and in age-matched unmanipulated rats $(90.1 \pm 2.2 \%$; $n=4)$. Alto- 

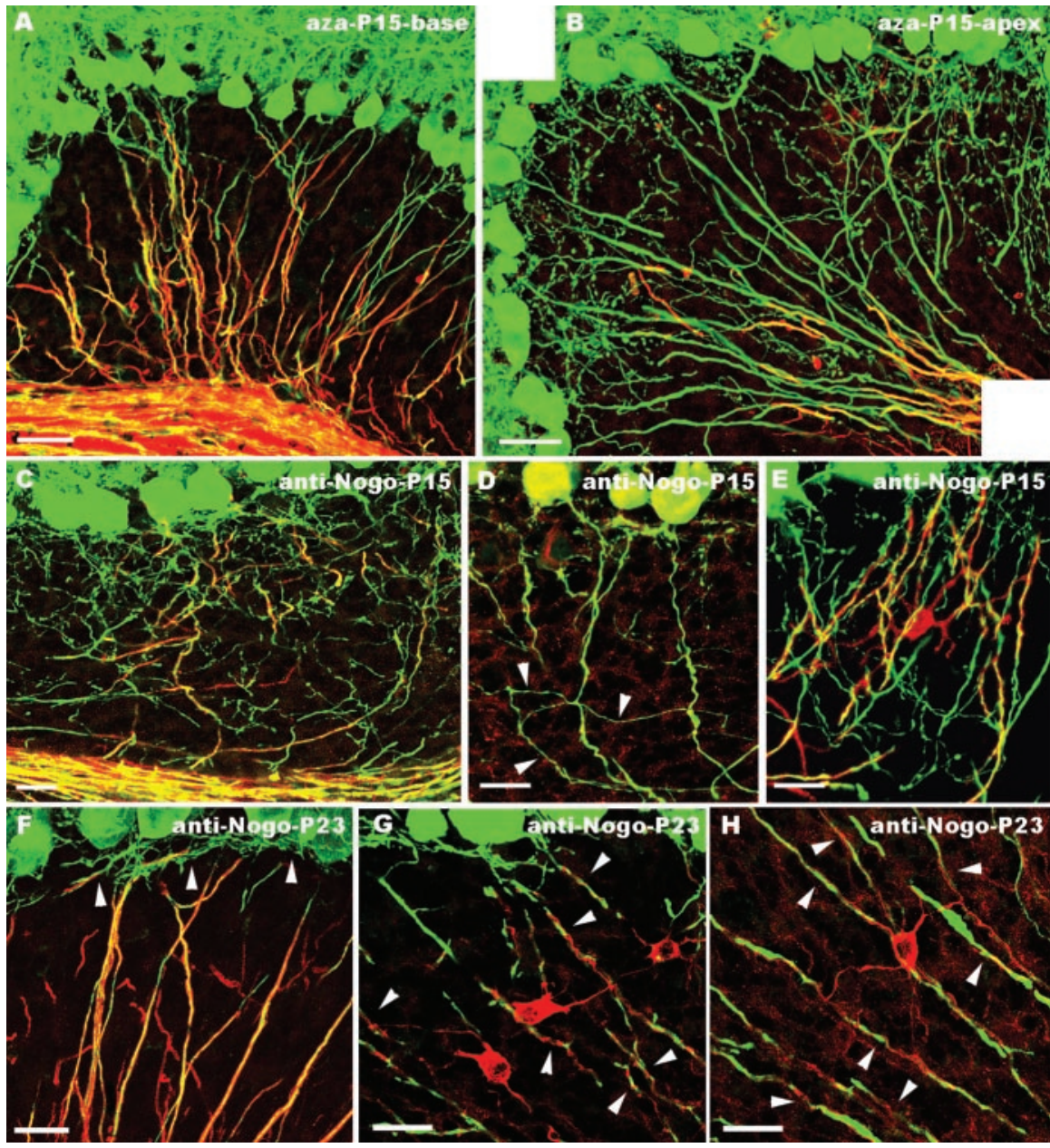

Figure 7. Morphology of Purkinje axon intracortical plexus after administration of $5^{\prime}$-azacytidine $(A, B)$ or application of anti-Nogo-A antibodies $(C-H)$. In the basal regions of cerebellar lobules from animals treated with $5^{\prime}$-azacytidine $(A)$, myelinogenesis (as shown by MBP staining, red) is almost normal, and Purkinje axons (green) show the mature distribution pattern. In contrast, in apical regions of the same lobules $(B)$, few MBP-positive processes are present in the granular layer, which is covered by numerous Purkinje axon profiles. $C-E$, Cerebellar regions close to the anti-Nogo-A injection site in animals killed $5 \mathrm{~d}$ after antibody injection (P15). Immunolabeling for MBP (C, red), Nogo-A (D, red; note the moderately stained Purkinje cell bodies), or CNP $(E$, red) shows sparse oligodendroglial profiles in the granular layer, where numerous Purkinje axon branches (green) remain (arrowheads in D point to collateral ramifications budding from a corticofugal axon). Numerous neuritic processes are also present in the vicinity of a CNP-positive oligodendrocyte in $E$. In rats killed $13 \mathrm{~d}$ after anti-Nogo-A injection (P23; $F-H)$, Purkinje neurites are covered by MBP-stained oligodendroglial processes $(F)$, whereas unmyelinated terminal branches (arrowheads) are confined within the upper granular layer. Anti-Nogo-A labeling of these cerebella $(G, H)$ shows strongly stained oligodendrocytes, whose processes (arrowheads) twine around Purkinje neurites. Confocal images are from double-labeled sections for calbindin (green) and $\operatorname{MBP}(A-C, F$, red), Nogo-A (D, G, H, red), and CNP (E, red). Scale bars: $F-H, 20 \mu \mathrm{m} ; C-E, 25 \mu \mathrm{m} ; A, B, 40 \mu \mathrm{m}$.

gether, these observations indicate that application of Nogo-A antibodies induced, in addition to Nogo-A neutralization, a delay in myelin maturation rather than oligodendrocyte death.

Finally, to ask whether the modifications of the Purkinje axon pattern induced by anti-Nogo-A antibodies were reversible, we examined another set of animals that received antibody injections at P10 and were killed at P23. In these rats, terminal branches of Purkinje axons were confined to the upper portion of the granular layer, whereas the corticofugal neurites coursing through the granular layer were covered by MBP-stained oligodendroglial processes (Fig. $7 F$ ). In addition, anti-Nogo-A labeling displayed strongly stained oligodendrocyte cell bodies and processes twining around Purkinje neurites (Fig. 7G,H). Quantitative evaluation showed no significant differences with control animals for all the morphometric parameters (Fig. 8C). Thus, the effects induced by a single application of anti-Nogo-A antibody made at $\mathrm{P} 10$ are transient, and the normal distribution pattern of myelin and Purkinje intracortical plexus is achieved within 2 weeks after injection.

\section{Discussion}

To investigate the mechanisms that regulate the shaping of specific neuritic patterns in the CNS, we examined the development of Purkinje intracortical plexus. Our results show that (1) collateral branches sprout from Purkinje axons during the first postnatal week and achieve their mature distribution after growth and pruning processes occurring during the following week; (2) the same basic ramification pattern is established by Purkinje cells grown in situ or in a foreign environment, suggesting that Purkinje axon growth is, at least in part, regulated by intrinsic mechanisms; and (3) the remodeling of Purkinje axons is concomitant with myelination, and experimental manipulations that prevent normal myelinogenesis produce an altered distribution of Purkinje axon collaterals. Thus, the mature pattern of Purkinje intracortical plexus results from complex interactions between cell-autonomous mechanisms and extrinsic cues, among which are oligodendrocyte molecules.

Development of Purkinje collateral branches: intrinsic mechanisms and extrinsic cues

After the description by Ramón y Cajal (1911), who first observed the transient redundancy of collateral branches, the development of Purkinje intracortical plexus has never been thoroughly characterized. Here we show that collateral branches originate as interstitial ramifications during early postnatal life. We were not able to examine individual Purkinje axons earlier than $\mathrm{P} 5$, and it is likely that some processes sprout at younger ages. Nevertheless, the numerous outgrowing profiles observed between $\mathrm{P} 5$ and $\mathrm{P} 8$, together with the absence of terminal branches in the upper granular layer before P10, indicate that the bulk of collateral ramifications are born during the second half of the first postnatal week.

Several reports indicate that branch sprouting is elicited by diffusible chemotropic signals, which also direct the navigation of newly formed processes (O'Leary et al., 1990; Acebes and Ferrus, 2000; Kalil et al., 2000; Özdinler and Erzurumlu, 2002; SoussiYanicostas et al., 2002). Nevertheless, certain neurons maintain typical neuritic patterns even in foreign territories (Acklin and Nicholls, 1990; Canal et al., 1998; Bhide and Frost, 1999), suggesting that the axon phenotype can be also regulated by cellautonomous mechanisms. The origin of Purkinje collateral branches in vivo is related to the distance from the cell body but not to the position in the granular layer. In addition, collateral branches with typical morphological features are developed both 
in dissociated cultures and after transplantation to extracerebellar CNS regions. The position of branching points is remarkably similar at $\mathrm{P} 8$ in vivo and in Purkinje cells grown in vitro, suggesting that this distance is encoded by an intrinsic growth program. On the other hand, the longer distances observed at $\mathrm{P} 15$ in vivo or after transplantation may be attributed to ensuing interstitial elongation of the Purkinje stem neurite, needed to compensate for the growth of the surrounding tissue.

Analysis of sensorimotor cortical neurons in vitro shows that advancing growth cones demarcate specific sites along the axon, characterized by lamellipodia-like swellings, from which delayed interstitial branching occurs (Szebenyi et al., 1998). Similar phenomena may also happen in Purkinje cells: both in vivo and in vitro, new processes sprout from focal swellings located along the corticofugal axon, indicating that collateral branches originate from precise neuritic segments specifically primed for this task. Interestingly, sprouting phenomena along the same neuritic region occur when anti-Nogo-A antibodies are applied to the adult cerebellum (Buffo et al., 2000), after axotomy in growth-associated protein-43-overexpressing mice (Buffo et al., 1997), and after inhibition of PKC in organotypic cultures (Ghoumari et al., 2002).

Although the typical Purkinje axon branching pattern can be established by Purkinje cells grown in vitro, it is unlikely that the development of Purkinje axons is exclusively determined by cellautonomous mechanisms. Many outgrowing processes in the granular layer in vivo are oriented toward the Purkinje cell layer, suggesting that they are subjected to attractive influences. Furthermore, the progressive withdrawal of collateral branches that occurs between P6 and P15 and the fact that many Purkinje axons lack such branches indicate that the formation and maintenance of recurrent ramifications require extrinsic support. Thus, our observations suggest that environmental cues elicit and sustain the growth of collateral ramifications, which sprout from intrinsically primed axon segments.

\section{Role of myelin in the structural remodeling of Purkinje intracortical plexus}

Structural remodeling of developing terminal arbors is generally related to the refinement of connectivity driven by patterned positional cues or activity- and experience-dependent mechanisms (Goodman and Shatz, 1993). Concerning Purkinje axon collaterals, the abnormally extended arborizations observed in the cerebellum of $\mathrm{x}$-irradiated rats have been attributed to the loss of granule cells, which are required for the plasticity of climbing fibers during the same developmental period (Crepel et al., 1980). Nevertheless, $\mathrm{x}$-irradiation during postnatal development affects
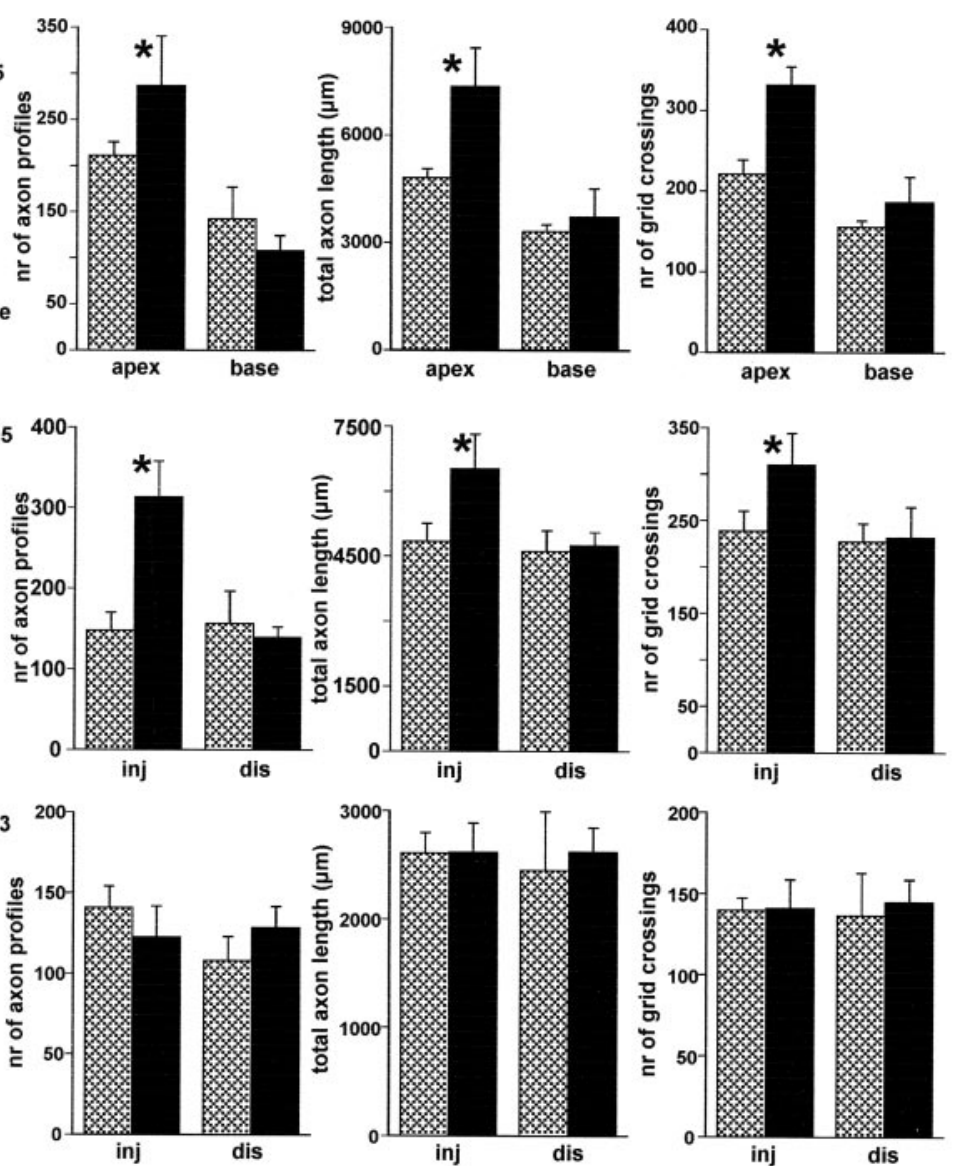

Figure 8. Morphometric evaluation of Purkinje axon intracortical plexus in 5' -azacytidine- and anti-Nogo-A-treated animals $A$, Different morphometric parameters evaluated in selected areas from basal and apical regions of cerebellar lobules from $5^{\prime}$ azacytidine-treated animals (solid bars, mean $\pm S D ; n=5$ ) and vehicle-injected control animals (hatched bars, mean $\pm S D ; n=$ $5 ;$ the diagram shows the approximate position of the examined areas). All parameters are significantly increased in the apica s, whereas no differences occur when basal regions are compared. $B$, Similar analysis performed on anti-Nogo-A-treated rats , mean \pm SD; $n=5$ ) or control antibody-treated rats (hatched bars, mean \pm SD; $n=4$ ) killed atP15 (5 d after antibody 列 antiberes occur in the distant regions. C, Results of the same analysis performed on animals killed at P23 (13 d after

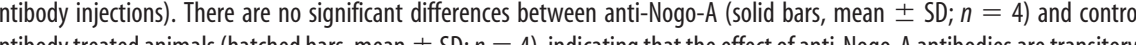
antibody treated animals (hatched bars, mean $\pm S D ; n=4$ ), indicating that the effect of anti-Nogo-A antibodies are transitory. Asterisks indicate values that are significantly different from the relevant control (see Results).

different cell types, including oligodendrocytes (Kapfhammer and Schwab, 1994b). We show here that after 5 -azacytidine treatment, which should touch proliferating cells similarly to $\mathrm{x}$-rays, altered intracortical arbors are confined within myelindevoid regions. In addition, similar neuritic changes are induced by anti-Nogo-A antibodies. Hence, although functional interactions with neighboring neurons or topographic cues (Hawkes and Leclerc, 1989) are likely important during Purkinje axon remodeling, our experiments indicate that oligodendrocytederived factors also contribute to shaping of intracortical arbors.

A direct action of anti-Nogo-A antibodies on Purkinje cells is possible but unlikely because of the very low level of protein expression in Purkinje axons and the strict similarity with $5^{\prime}$ azacytidine-induced changes. On the other hand, the reduced amount of oligodendrocytes in the granular layer of anti-NogoA-treated cerebella could suggest that these cells were killed by the antibody. Although this cannot be completely excluded, the lack of morphological evidence for myelin degeneration, together 
with the normal amount of myelinated axons in the white matter of the lobules surrounding the injection site, argue against this possibility. Rather, our results indicate that anti-Nogo-A antibodies induced a delay of oligodendroglial maturation, suggesting that Nogo-A-mediated mechanisms may be also important for myelin development. In addition, the observation of exuberant Purkinje axon profiles in the granular layer in the vicinity of oligodendrocytes supports the view that the neuritic alterations are, at least in part, directly related to functional neutralization of Nogo-A.

It is uncertain whether myelin-derived factors or other oligodendrocyte molecules, actively induce the pruning of Purkinje axon branches or whether they just stabilize mature neurites, preventing further growth. Similarly, it is difficult to establish whether the numerous axon profiles present in the myelindeprived granular layer are preexisting processes that failed to withdraw or newly formed sprouts issued after the neutralization of oligodendrocyte-derived inhibition. Adult Purkinje cells show a strong inclination to sprouting that can be revealed by application of different antibodies directed against inhibitory molecules (Buffo et al., 2000) or after the appearance of growth-promoting cues (Dusart and Sotelo, 1994; Dusart et al., 1999; Gianola and Rossi, 2002). Consequently, the interaction between intrinsic properties of Purkinje cells and growth-stimulating environmental signals may trigger the sprouting of new processes. In this context, oligodendrocyte molecules may be important to confine neuritic plasticity within well defined cortical domains. Nogo-A, whose receptor is expressed by adult Purkinje cells (Fournier et al., 2001), is localized in the innermost and outermost myelin membranes (Huber et al., 2002; Wang et al., 2002) so that it can exert both a tonic stabilizing function on the axon shaft and growth-arresting activity on other incoming processes (Bandtlow et al., 1990, 1993).

Main targets for Purkinje axon collaterals are Purkinje cells and different types of neurons in the upper granular and lower molecular layers (Palay and Chan-Palay, 1974; King and Bishop, 1982). After injury, however, Purkinje axons form heterotypic contacts with granule cells (Dusart et al., 1999), suggesting that they may compete with mossy fibers for postsynaptic space. Hence, during development, the centrifugally directed maturation of myelin would progressively restrain intracortical plexus toward the superficial portion of the granular layer. In the adult, the dense network of oligodendroglial processes may function as a barrier to prevent Purkinje axon branches from entering forbidden cortical domains. Interestingly, in lobules IX and X, where Purkinje axon plexus spans the entire granular layer, the density of MBP-labeled oligodendroglial processes is lower than in other cortical regions (Rossi et al., 2001).

Consistent with previous observations relating myelin deposition in the mammalian CNS to the end of critical periods for developmental plasticity (Müller et al., 1994), here we provide evidence that correct myelination is a necessary prerequisite for the proper accomplishment of physiological remodeling of developing CNS axons. Although it is likely that myelination is not the only factor responsible for restricting the neuritic growth potential of maturing central neurons (Fawcett, 2001; KarimiAbdolrezaee and Schreyer, 2002), it is clear that it exerts a fundamental role in confining plastic phenomena within defined CNS domains to prevent unwanted growth and to maintain synaptic specificity. Neutralization of this inhibition to promote regeneration might thus lead to the formation of abnormal connections with possible detrimental effects on functional recovery. Nevertheless, the growth-promoting effect of anti-Nogo-A antibodies on intact neurons is primarily transitory and reversible (Buffo et al., 2000; Bareyre et al., 2002; this study), and properly patterned projections can be established by compensatory sprouting (Thallmair et al., 1998; Z'Graggen et al., 1998). This suggests that temporary suppression of this inhibition may be compatible with full anatomical repair and functional recovery.

\section{References}

Acebes A, Ferrus A (2000) Cellular and molecular features of axon collaterals and dendrites. Trends Neurosci 23:557-564.

Acklin SE, Nicholls JG (1990) Intrinsic and extrinsic factors influencing properties and growth patterns of identified leech neurons in culture. J Neurosci 10:1082-1090.

Altman J, Bayer SA (1985) Embryonic development of the rat cerebellum. III. Regional differences in the time of origin, migration, settling of Purkinje cells. J Comp Neurol 231:42-65.

Altman J, Bayer SA (1997) Development of the cerebellar system in relation to its evolution, structure and functions. New York: CRC.

Bandtlow C, Zachleder T, Schwab ME (1990) Oligodendrocytes arrest neurite growth by contact inhibition. J Neurosci 10:3837-3848.

Bandtlow C, Schmidt MF, Hassinger TD, Schwab ME, Kater SB (1993) Role of intracellular calcium in NI-35-evoked collapse of neuronal growth cones. Science 259:80-83.

Bareyre FM, Haudenshild B, Schwab ME (2002) Long-lasting sprouting and gene expression changes induced by the monoclonal antibody IN-1 in the adult spinal cord. J Neurosci 22:7097-7110.

Bernstein M, Lichtman JW (1999) Axonal atrophy: the retraction reaction. Curr Opin Neurobiol 9:364-370.

Bhide PG, Frost DO (1999) Intrinsic determinants of retinal axon collateralization and arborization patterns. J Comp Neurol 411:119-129.

Buffo A, Holtmaat AJDG, Savio T, Verbeek S, Oberdick J, Oestreicher AB, Gispen WH, Verhaagen J, Rossi F, Strata P (1997) Targeted overexpression of the neurite growth-associated protein B-50/GAP-43 in cerebellar Purkinje cells induces sprouting in response to axotomy but does not allow axon regeneration into growth permissive transplants. J Neurosci 17:8778-8791.

Buffo A, Zagrebelsky M, Huber AB, Skerra A, Schwab ME, Strata P, Rossi F (2000) Application of neutralizing antibodies against NI-35/250 myelinassociated neurite growth inhibitory proteins to the adult rat cerebellum induces sprouting of uninjured Purkinje cell axons. J Neurosci 20:2275-2286.

Canal I, Acebes A, Ferrùs A (1998) Single neuron mosaics of the Drosophila gigas mutant project beyond normal targets and modify behavior. J Neurosci 18:999-1008.

Carletti B, Grimaldi P, Magrassi L, Rossi F (2002) Specification of cerebellar progenitors following heterotopic/heterochronic transplantation to the embryonic CNS in vivo and in vitro. J Neurosci 22:7132-7146.

Chen MS, Huber AB, van der Haar ME, Frank M, Schnell L, Spillmann AA, Christ F, Schwab ME (2000) Nogo-A is a myelin-associated neurite outgrowth inhibitor and antigen for monoclonal antibody IN-1. Nature 403:434-439.

Colello RJ, Schwab ME (1994) A role for oligodendrocytes in the stabilization of optic axon numbers. J Neurosci 14:6446-6452.

Crepel F, Delhaye-Bouchaud N, Dupont JL, Sotelo C (1980) Dendritic and axonic fields of Purkinje cells in developing and X-irradiated rat cerebellum. A comparative study using intracellular staining with horseradish peroxidase. Neuroscience 5:333-347.

Davies AM (1994) Intrinsic programmes of growth and survival in developing vertebrate neurons. Trends Neurosci 17:195-199.

Dawson MRL, Levine JM, Reynolds R (2000) NG2-expressing cells in the central nervous system: are they oligodendroglial progenitors? J Neurosci Res 61:471-479.

Dusart I, Sotelo C (1994) Lack of Purkinje cell loss in adult rat cerebellum following protracted axotomy: degenerative changes and reactive attempts of the severed axons. J Comp Neurol 347:211-232.

Dusart I, Morel MP, Wehrlé R, Sotelo C (1999) Late axonal sprouting of injured Purkinje cells and its temporal correlation with permissive changes in the glial scar. J Comp Neurol 408:399-418.

Eisenman LM, Schalekamp MPA, Voogd J (1991) Development of the cerebellar cortical efferent projection: an in vitro study in rat brain slices. Dev Brain Res 60:261-266.

Fawcett JW (2001) Intrinsic control of regeneration and the loss of regener- 
ative ability in development. In: Axonal regeneration in the central nervous system (Ingoglia NA, Murray M eds), pp 161-183. New York: Dekker.

Fournier AE, GrandPre T, Strittmatter SM (2001) Identification of a receptor mediating Nogo-66 inhibition of axonal regeneration. Nature 409:341-346.

Ghoumari AM, Wehrlé R, De Zeeuw CI, Sotelo C, Dusart I (2002) Inhibition of protein kinase $\mathrm{C}$ prevents Purkinje cell death but does not affect axonal regeneration. J Neurosci 22:3531-3542.

Gianola S, Rossi F (2001) Evolution of the Purkinje cell response to injury and regenerative potential during postnatal development of the rat cerebellum, J Comp Neurol 430:101-117.

Gianola S, Rossi F (2002) Long-term injured Purkinje cells are competent for terminal arbour growth, but remain unable to sustain stem axon regeneration. Exp Neurol 176:25-40.

Gianola S, Savio T, Rossi F (2002) Cell-autonomous mechanisms and environmental cues in the development of Purkinje axon collateral branches. Soc Neurosci Abstr 28:129.9.

Goodman CS, Shatz CJ (1993) Developmental mechanisms that generate precise patterns of neuronal connectivity. Cell [Suppl] 10:77-98.

Gravel C, Leclerc N, Plioplys A, Hawkes RB (1986) Focal axonal swellings in rat Purkinje cells during normal development. Brain Res 363:325-332.

Hatten ME, Gao W-Q, Morrison ME, Mason CA (1998) The cerebellum: purification and coculture of identified cell populations. In: Culturing nerve cells (Banker G, Goslin K, eds) pp 419-459. Cambridge, MA: MIT.

Hawkes RB, Leclerc N (1989) Purkinje axon collateral distributions reflect the chemical compartmentation of the cerebellar cortex. Brain Res 476:279-290.

Huber AB, Schwab ME (2000) Nogo-A, a potent inhibitor of neurite growth and regeneration. Biol Chem 381:407-419.

Huber AB, Weinmann O, Brösamle, Oertle T, Schwab ME (2002) Patterns of Nogo mRNA and protein expression in the developing and adult rat and after CNS lesions. J Neurosci 22:3553-3567.

Inouye M, Murakami U (1980) Temporal and spatial patterns of Purkinje cell formation in the mouse cerebellum. J Comp Neurol 194:499-503.

Ji Z, Hawkes RB (1996) Partial ablation of the neonatal external granular layer disrupts mossy fibre topography in the adult rat cerebellum. J Comp Neurol 371:578-588.

Kalil K, Szebenyi G, Dent EW (2000) Common mechanisms underlying growth cone guidance and axon branching. J Neurobiol 44:145-158.

Kapfhammer JP, Schwab ME (1994a) Inverse patterns of myelination and GAP-43 expression in the adult CNS: neurite growth inhibitors as regulators of neuronal plasticity? J Comp Neurol 340:194-206.

Kapfhammer JP, Schwab ME (1994b) Increased expression of growthassociated protein GAP-43 in myelin-free rat spinal cord. Eur J Neurosci 6:403-411.

Karimi-Abdolrezaee S, Schreyer DJ (2002) Retrograde repression of growth-associated protein- 43 mRNA expression in rat cortical neurons. J Neurosci 22:1816-1822.

King JS, Bishop GA (1982) The synaptic features of horseradish peroxidaselabelled recurrent collaterals in the ganglionic plexus of the cat cerebellar cortex. J Neurocytol 11:867-880.

Levine JM, Stincone F, Lee Y-S (1993) Development and differentiation of glial precursor cells in rat cerebellum. Glia 7:307-321.

Lichtman JW, Colman H (2000) Synapse elimination and indelible memory. Neuron 25:269-278.

Müller CM, Gardziella S, Schwab ME (1994) Role of the myelin-associated neurite growth inhibitor NI35/250 in the determination of critical period plasticity in kitten visual cortex. Soc Neurosci Abstr 20:1471.

O'Leary DDM, Bicknese AR, De Carlos JA, Heffner CD, Koester SE, Kutka LJ, Terashima T (1990) Target selection by cortical axons: alternative mechanisms to establish connections in the developing brain. Cold Spring Harb Symp Quant Biol 55:453-468.

Özdinler PH, Erzurumlu RS (2002) Slit2, a branching-arborization factor for sensory axons in the mammalian CNS. J Neurosci 22:4540-4549.

Palay SL, Chan-Palay V (1974) Cerebellar cortex: cytology and organization. Berlin: Springer.

Ramón y Cajal S (1911) Histologie du système nerveux de l'homme et des vertébrés. Paris: Maloine.

Reynolds R, Wilkins GP (1988) Development of macroglial cell in rat cerebellum. II. An in situ immunohistochemical study of oligodendroglial lineage from precursor to mature myelinating cell. Development 102:409-425.

Riley DA (1981) Ultrastructural evidence for axon retraction during the spontaneous elimination of polyneuronal innervation of the rat soleus muscle. J Neurocytol 10:425-440.

Rossi F, Borsello T, Vaudano E, Strata P (1993) Regressive modifications of climbing fibres following Purkinje cell degeneration in the cerebellar cortex of the adult rat. Neuroscience 53:759-778.

Rossi F, Buffo A, Strata P (2001) Regulation of intrinsic regenerative properties and axonal plasticity in cerebellar Purkinje cells. Restor Neurol Neurosci 19:85-94.

Savio T, Schwab ME (1989) Rat CNS white matter, but not gray matter, is nonpermissive for neuronal cell adhesion and fiber outgrowth. J Neurosci 9:1126-1133.

Schwab ME, Schnell L (1991) Channeling of developing corticospinal tract axons by myelin-associated neurite growth inhibitors. J Neurosci 11:709-721.

Schwab ME, Kapfhammer JP, Bandtlow CE (1993) Inhibitors of neurite growth. Annu Rev Neurosci 16:565-595.

Schwegler G, Schwab ME, Kapfhammer JP (1995) Increased collateral sprouting of primary afferents in myelin-free spinal cord. J Neurosci 15:2756-2767.

Shen YJ, DeBellard ME, Salzer JL, Roder J, Filbin MT (1998) Myelinassociated glycoprotein in myelin and expressed by Schwann cells inhibits axonal regeneration and branching. Mol Cell Neurosci 12:79-91.

Sotelo C (1990) Cerebellar synaptogenesis: what can we learn from mutant mice? J Exp Biol 153:225-249.

Soussi-Yanicostas N, de Castro F, Julliard AK, Perfettini I, Chédotal A, Petit C (2002) Anosmin-1, defective in the X-linked form of Kallmann syndrome, promotes axonal branch formation from olfactory bulb output neurons. Cell 109:217-228.

Szebenyi G, Callaway JL, Dent EW, Kalil K (1998) Interstitial branches develop from active regions of the axon demarcated by the primary growth cone during pausing behaviors. J Neurosci 18:7930-7940.

Thallmair M, Metz GAS, Z’Graggen WJ, Raineteau O, Kartje GL, Schwab ME (1998) Neurite growth inhibitors restrict plasticity and functional recovery following corticospinal tract lesions. Nat Neurosci 1:124-131.

Vanek P, Thallmair M, Schwab ME, Kapfhammer JP (1998) Increased lesion-induced sprouting of corticospinal fibres in the myelin-free spinal cord. Eur J Neurosci 10:45-56.

Wang X, Chun S-J, Treloar H, Vartanian T, Greer CA, Strittmatter SM (2002) Localization of Nogo-A and Nogo-66 receptor proteins at sites of axon-myelin and synaptic contact. J Neurosci 22:5505-5515.

Zagrebelsky M, Buffo A, Skerra A, Schwab ME, Strata P, Rossi F (1998) Retrograde regulation of growth-associated gene expression in adult rat Purkinje cells by myelin-associated neurite growth-inhibitory proteins. J Neurosci 18:7912-7929.

Z'Graggen WJ, Metz GAS, Kartje GL, Thallmair M, Schwab ME (1998) Functional recovery and enhanced corticofugal plasticity after unilateral pyramidal tract lesion and blockade of myelin-associated neurite growth inhibitors in adult rats. J Neurosci 18:4744-4757. 